\title{
PERCURSOS ACELERADOS DE JOVENS CONDUTORES ILEGAlS: O RISCO ENTRE VIDA E MORIE, ENTRE JOGO E RITO
}

\author{
Leila Sollberger Jeolás \\ Universidade Estadual de Londrina - Brasil
}

\author{
Hagen Kordes \\ Westfälische Wilhelms-Universität Münster-Alemanha
}

\begin{abstract}
Resumo: Com base em uma pesquisa de cunho etnográfico sobre "rachas" de carros e de motos, propomos questionar se a aceleração dos motores pode ser pensada como uma metáfora para a aceleração dos percursos fluidos, flexíveis e incertos desses jovens, próprios do contexto da "sobremodernidade". O objetivo é de compreender os significados atribuídos à experiência da velocidade e ao risco aí envolvido, a fim de analisar a relação entre condutas de risco juvenis e o papel dos ritos de passagem, conceito-chave na antropologia. Discutiremos o alcance e os limites de se compreender os "rachas", por um lado, como uma forma individualizada de ritualizar a passagem da infância à idade adulta e, por outro, como a expressão lúdica de uma forma de jogo-brinquedo. Como outras formas de culturas juvenis, os "rachas" podem ser compreendidos como linguagem de singularização e de pertencimento reforçada por valores e práticas de uma masculinidade hegemônica tradicional.
\end{abstract}

Palavras-chave: aceleração, percursos, risco, ritos de passagem.

\begin{abstract}
This ethographic study about the "rachas" of motos and cars is grounded around the question, if and in how far the acceleration of motors could serve as a methaphor for the acceleration of fluid, flexible and undetermined par-courses of life in the context of "surmodern" societies. The objective is first to understand the significations given to the experiences of speed and of the risks implied, in order to analyse then the relationship between the youth's risk conduct and the rites of passage. We will discuss the potentialities and limits of comprehending the "rachas" on one side as an individualised form of a passage ritual and on the other side as a ludicrous expression of play and joy. Thus we could interpret the "rachas" like other varieties of youth culture as a language of singularisation and affiliation emphasized by practices of traditional hegemonic masculinity.
\end{abstract}

Keywords: acceleration, par-courses, risk, rite of passage. 


\section{Introducão}

A pesquisa sobre "rachas" de carros e de motos, ${ }^{1}$ cujo objetivo geral é de analisar os significados que os jovens atribuem à velocidade e ao risco aí implicado, inspirou vários questionamentos sobre os percursos arris$\operatorname{cados}^{2}$ desses jovens. Propomos, nos limites deste artigo, questionar se a busca da velocidade e da aceleração pode ser pensada como uma metáfora para os percursos de vida fluidos, flexíveis e incertos, próprios do contexto da "sobremodernidade". ${ }^{3}$ A partir da apresentação de alguns jovens "rachadores", discutiremos a relação entre condutas de risco juvenis e o papel dos ritos de passagem, conceito-chave na antropologia, examinando se ele é profícuo para a análise de fenômenos relativos à juventude no contexto atual.

Conceituar juventude se tornou uma tarefa complexa, em função da dificuldade de precisar seus limites iniciais e finais em face das profundas transformações sofridas pelos jovens atualmente. Para expressar essas mudanças, é esclarecedora a metáfora utilizada sobre a evolução dos transportes: no pós-guerra europeu as transições para a vida adulta podiam ser comparadas às viagens de trem, nas quais os jovens, dependendo do seu capital econômico e cultural, escolhiam destinos predeterminados; depois dessa época, as

\footnotetext{
1 A pesquisa etnográfica sobre "rachas" - os clandestinos, ou de rua, e aqueles que ocorrem no autódromo - foi realizada na cidade de Londrina (PR), entre 2007 e 2009. A pesquisa utilizou-se de várias técnicas e abordagens: pesquisa na internet em comunidades que têm o "racha" como foco de interesse; pesquisa de campo realizada com ajuda de um estudante, também "rachador", que serviu de guia e de assistente de pesquisa; observação e elaboração de caderno de campo; conversas informais e entrevistas formais registradas e transcritas; e registro de fotos e vídeos (Jeolás, 2008).

2 Utilizaremos o termo "percurso" como conceito que abrange as diversas trajetórias (familiais, escolares, profissionais, religiosas) realizadas pelos sujeitos sociais entre a infância e a idade adulta. No sentido que lhe atribuem Sapin, Spini e Widmer (2007), o "percurso de vida" é composto de várias trajetórias e se refere a todo o processo que se desenvolve ao longo da vida de um indivíduo, podendo melhor expressar a fluidez, a incerteza e a precariedade próprias das biografias atuais. A associação do termo "percurso" ao adjetivo "arriscado" refere-se tanto ao risco presente na velocidade alcançada e nas manobras realizadas pelos jovens "rachadores" como à incerteza dos percursos de vida em face das transformações sociais atuais.

3 O termo "sobremodernidade" será utilizado, nesse artigo, de maneira provisória, no sentido que lhe atribuiu Augé (1994), como excesso de tempo, de espaço e de referências, mas também com relação às várias transformações ocorridas nas sociedades ocidentais contemporâneas e analisadas por diferentes autores: excesso (Augé, 1994; Balandier, 1994), aceleração (Virilio, 1996), individualização e reflexividade (Beck, 1986; Beck, Beck-Gernsheim; 2000; Giddens; Beck; Lash, 1997), flexibilização (Sennett, 2001), mundialização (Appadurai, 1999; Featherstone, 1999).
}

Horizontes Antropológicos, Porto Alegre, ano 16, n. 34, p. 159-187, jul./dez. 2010 
transições dos jovens podiam ser comparadas a viagens de automóveis, nas quais o condutor pode selecionar o seu itinerário entre um vasto número de alternativas, também dependendo de suas condições; atualmente, as transições são múltiplas, como em um labirinto rodoviário, no qual há sentidos obrigatórios e proibidos, alterações de trânsito, caminhos já utilizados e retomados, outros sem saída, provocando sensações de confusão, de reversibilidade e movimentos de vaivém ininterruptos. ${ }^{4}$

Nesse sentido, há um consenso entre vários autores de que as características das sociedades ocidentais contemporâneas afetam as transições dos percursos de vida, que não são mais claramente demarcadas por ritos comuns. As passagens são múltiplas, os percursos indeterminados ${ }^{5}$ e os ritos são "bricolados" pelos sujeitos, a partir de referências tradicionais e novas, na busca do sentido de sua existência, não podendo mais contar com ritos unívocos que propiciam significações coletivas.

De acordo com a bibliografia sobre o tema, os ritos atuais marcariam as passagens de maneira mais individual do que coletiva, de forma mais privada do que pública, possibilitando reforçar a construção de uma identidade original e individual, mas não um sentido de pertencimento coletivo ou de mudança de status social. ${ }^{6}$ Em uma sociedade que não propicia referências estáveis, caberia aos jovens prefigurar eles próprios essas referências a partir de suas possibilidades e das circunstâncias existentes. Cabe, então, examinar se os percursos dos jovens "rachadores" apresentam essas mesmas características descritas e quais são os processos de bricolagem que realizam para poder atribuir sentido às suas vidas, à semelhança das bricolagens que fazem para transformar seus carros e motos. E, mais importante, cabe examinar o papel das condutas de risco nas possíveis ritualizações de passagem que esses jovens estariam realizando.

4 Metáfora utilizada pelo sociólogo Machado Pais (2006).

5 As passagens ou transições para a vida adulta são descritas através dos processos de: constituição de uma identidade pessoal e social; orientação e inserção profissionais; criação de uma entidade familiar e residencial; autonomização pessoal (Marques, 2003).

6 A propósito dessa privatização e flexibilização dos ritos, Segalen $(2009$, p. 48) exemplifica como o casamento marcava antes (ou em outras sociedades) uma passagem de status e, atualmente, apesar de continuar a ser celebrado, tem outro sentido, o de tornar público um ato de engajamento decidido pelo casal há algum tempo e através de pequenas etapas. Nas palavras da autora, "un rituel aux flexibilités jusqu'alors inconnues permet à chaque couple de mettre en scène son propres mariage".

Horizontes Antropológicos, Porto Alegre, ano 16, n. 34, p. 159-187, jul./dez. 2010 
Para tanto, tomamos como ponto de partida a proposta de Le Breton (2003, 2007a, 2007b), que compreende as condutas de risco juvenis - uso de álcool e de drogas, atitudes de violência, tentativas de suicídio, distúrbios alimentares - como manifestações de ritos individuais de passagem. Para o autor, uma parcela significativa de jovens sofre, atualmente, dificuldades para se integrar à ordem social e sente-se "em suspenso" e incerta quanto ao seu futuro, não podendo contar com respostas coletivamente elaboradas a propósito do valor e do sentido de sua existência. Eles recorreriam, dessa forma, segundo Le Breton (2003, p. 50), a "une forme clandestine et solitaire de symbolisation du goût de vivre".

Esse gosto de viver seria reencontrado no jogo inconsciente de interpelar a morte sobre o significado da vida e estaria presente, justamente, nessas condutas de risco. De acordo com o autor, contrariamente aos ritos de passagem tradicionais, essa interpelação da morte produzida por esses novos ritos solitários, se bem-sucedidos, quer dizer, se não levarem à morte, permite aos jovens a realização de uma "metamorfose de si" (sempre provisória) que atribui um novo significado à sua vida, mas que não se transmite aos outros. Nas palavras de Le Breton (2003, p. 52), trata-se de "l'unes des formes de cristallisation moderne de l'identité quand tout le reste se dérobe".

Um dos pressupostos de nossa análise, entretanto, é a de que as condutas de risco praticadas pelos jovens "rachadores" não podem ser suficientemente explicadas como ritos individuais de passagem, mas tampouco se enquadram no modelo dos ritos de passagem tradicionais. É aqui que introduzimos uma interpretação mais extensiva, a fim de melhor compreender essas práticas como ritos permanentes de virilidade, conceito também desenvolvido por Le Breton (2009, p. 35), mas, ao mesmo tempo, como jogo-brincadeira.

Por um lado, os "rachas" podem ser analisados como ritos permanentes de virilidade, no sentido de ritos intermediários, que têm a função de marcar não a passagem de uma fase ou de um status a outro, mas a entronização em grupos de pares e com característica de "contrabando" (Le Breton, 2007b, p. 79, 2009, p. 39), quer dizer, a de serem reprovados pelas instituições sociais. O nosso pressuposto central é o de que esses ritos potencializam o risco existente nessas práticas, porque eles exigem permanentemente a comprovação pública de alguns dos valores centrais ao modelo de masculinidade hegemônico tradicional, como a coragem e a competitividade (Almeida, 2000; Connell, 1997; Espada Calpe, [s.d.]; Kimmel, 1998), através dos desafios lançados para "tirar racha". 
Por outro lado, os "rachas" são também vividos como "brincadeira", de acordo com as palavras dos jovens pesquisados. Essa dimensão de jogobrincadeira remete à discussão da relação existente entre rito e jogo. Verificar como ela se manifesta nos "rachas", sobretudo na vertente lúdica de jogo denominado por Caillois (1986) de mimesis, é fundamental por três razões. Primeiramente, pelo fato desse estreito elo existente entre rito e jogo ser foco de análise de vários autores (St-Germain; Ménard, 2008), desde os trabalhos de Huizinga (1963) e de Caillois (1986). Em seguida, porque a cultura contemporânea manifesta várias formas lúdicas que têm características de jogos - dos esportes aos jogos eletrônicos -, embaralhando ainda mais os limites com as formas rituais. E, finalmente, porque essa relação emerge de forma marcante e complexa do material de campo analisado.

Vale ressaltar que no universo da velocidade, contrariamente às abordagens que colocam o risco como resposta ao sofrimento, os jovens enfatizam também o lado da "brincadeira", do "divertimento", do "prazer", do "saberfazer" e do domínio do homem sobre a máquina. Eles pouco falam de risco e, quando o fazem, é no sentido de controle do risco, através da competência técnica. Tão só por essa razão, essa abordagem já seria necessária, pois como bem ressalta Peirano (2003, p. 8), ao analisar os rituais, ontem e hoje, é mais prudente não dar uma definição de ritual a priori, de maneira absoluta e rígida (e diríamos o mesmo para o jogo), pois "a compreensão do que é um ritual não pode ser antecipada, ela precisa ser etnográfica, isto é, apreendida pelo pesquisador em campo junto ao grupo que ele observa".

Para proceder à análise dos percursos dos jovens "rachadores", elegemos, a partir do material de campo, três movimentos de oscilação de sentido: o risco entre rituais de passagem e passagens indeterminadas; o risco entre vertigem e controle; e o risco entre vida e morte e entre rito e jogo. Essas três oscilações apontam para os percursos "sobremodernos" desses jovens, no sentido de que as passagens se fazem de maneira cada vez mais indeterminada sem, no entanto, destruírem os ritos de passagem, mas sim os reestruturando e fazendo-os mover-se, alternadamente, entre o privado e o público, o individual e o coletivo. Poderíamos falar em uma rerritualização. Além disso, os percursos estão inseridos em redes de sociabilidade que oscilam entre as mais indeterminadas e as mais estáveis, sem, entretanto, que as primeiras façam desaparecer as segundas.

Essas oscilações só podem ser bem compreendidas no campo das abordagens da teoria da prática, justamente as que nos guiam nessa análise. As teorias 
da prática buscam compreender o entrelaçamento das coerções socioculturais e das ações dos sujeitos. Dar conta dessa interdependência entre as forças de transformação mais amplas da vida social e as dimensões das interações dos atores sociais não é tarefa das mais fáceis e o desafio é, justamente, segundo Ortner (2007, p. 50), construir uma análise das práticas sociais em que "nem os 'indivíduos' nem as 'forças sociais' têm 'precedência', mas na qual há, contudo, uma relação dinâmica, forte e, às vezes, transformadora entre as práticas de pessoas reais e as estruturas da sociedade, da cultura e da história".

\section{Os percursos arriscados de jovens "rachadores"7}

A pesquisa de campo foi realizada em quatro locais da cidade de Londrina (PR): uma rodovia em frente a uma boate, cujos "rachas" se dão entre motos de baixa cilindrada; uma outra rodovia em frente a uma empresa, na qual a frequência é também de motos de baixa cilindrada; uma praça onde se encontram os jovens do Londrina Tuning $\mathrm{Club}^{8}$ e realizam manobras como o burnout ${ }^{9}$ e, por vezes, combinam encontros para "tirar rachas"; e o Autódromo Internacional Ayrton Senna, com os eventos dos "rachas" quinzenais.

Os "rachas" de rua acontecem ou de maneira imprevisível, no calor da hora, a partir de sinais de luz e acelerações diante de um sinal fechado, por exemplo, ou são combinados antecipadamente. Eles ocorrem normalmente

\footnotetext{
A não ser pelo fato de serem todos do sexo masculino, o perfil dos "rachadores" é variável, a começar pela faixa etária, que vai de 18 a 40 anos. No universo das motos de baixa cilindrada prevalecem os jovens das classes populares, que utilizam suas motos para o trabalho e para os "rachas"; no universo dos carros, há jovens das classes populares, jovens de camadas mais baixas da classe média, com carros velhos reparados e "preparados" à medida de suas possibilidades, e jovens com maior poder aquisitivo e carros novos "turbinados".

8 O tuning ou o carro "tunado" refere-se às modificações produzidas no motor para aumentar sua potência e também através de acessórios acrescentados para melhorar a aerodinâmica e promover desempenho. Entretanto, dada a difusão e a moda do tuning, muitos carros são atualmente modificados para fins de exposição e raramente usados para correr. Hoje em dia, o tuning implica normalmente alterações visuais dos pneus por diâmetros maiores, kits de carroçaria, interiores totalmente revistos, rebaixamentos da carroçaria, dentre outros, de forma a distinguir os carros dos demais, diferenciando-os do original e ganhando personalidade.

9 Termo em inglês que se refere à manobra de queimar pneus com o carro parado até estourarem. Em português, a prática é também conhecida como "borrachão". Pudemos perceber aí os elementos de destruição, agonismo e prestígio, como nos potlach analisados por Mauss (1974), mas potlatch em uma sociedade de classe e de mercado, na qual os jovens só podem fazer o burnout com pneus usados e velhos que seriam descartados, a não ser que tivessem poder aquisitivo para comprar pneus novos.
}

Horizontes Antropológicos, Porto Alegre, ano 16, n. 34, p. 159-187, jul./dez. 2010 
tarde da noite, quando as ruas têm menos movimento, e se constituem práticas ilegais, podendo acarretar multas e a apreensão do carro. No autódromo, os "rachas" são eventos quinzenais, pagos, normatizados e legalizados. São organizados por um amante dessa prática que arrenda do setor público uma das pistas e garante a presença de ambulância e de bombeiros para socorro, em caso de necessidade, e de seguranças privados. ${ }^{10}$

As redes de sociabilidade se constroem em torno desses encontros e eventos e também em torno de oficinas mecânicas especializadas em "turbinar" carros e motos, postos de gasolina, encontros regulares promovidos pelos clubes locais dos "dodgeros" e "opaleros", dentre outros. Os conflitos de classe perpassam as diferenças de estilos, aparecendo nas referências aos jovens que têm carros mais novos "tunados" como "filhinhos de papai", nas referências aos jovens de classes populares, com as motos de baixa cilindrada ou carros mais velhos, como o Chevette, de "manos", identificados à periferia.

O perfil dos jovens motoqueiros que frequentam as duas rodovias é mais ou menos homogêneo. São jovens de classes populares, todos na faixa etária de 16 a 25 anos, possuem moto de baixa cilindrada (Honda $125 \mathrm{cc}$, Titan, Honda Biz), as mais baratas do mercado, cuja venda é facilitada em muitas prestações. Esses jovens, em sua maioria, são moradores da periferia, estudam e trabalham, muitos utilizam a moto também como instrumento de trabalho, realizando entregas durante o dia ou à noite. Há um predomínio de quase $100 \%$ de jovens do sexo masculino pilotando as motos, embora as garotas estejam presentes, ou nas garupas das motos, ou os acompanhando para assistir, principalmente no primeiro local citado. ${ }^{11}$

Há também jovens de camadas mais baixas das classes médias que possuem carros antigos reparados e "preparados" para os "rachas" e, por vezes,

${ }^{10}$ Ele arrenda uma das retas do autódromo, com 400 metros de comprimento, em frente aos boxes. O objetivo, segundo ele, é justamente o de diminuir, senão eliminar, os "rachas" de rua, por conta do risco que eles representam tanto para quem pratica como para outros motoristas e transeuntes. Esses "rachas" têm um aspecto de "arrancadas", pois os motoristas se inscrevem e "arrancam" de dois em dois nessa reta. É permitida a participação de qualquer tipo de carro ou de moto, sendo necessário apenas que as duplas de motoristas que querem competir apresentem suas carteiras de habilitação ao se inscreverem.

${ }^{11}$ É comum ver essas motos personalizadas com adesivos, aros pintados de cores fluorescentes (laranja, cor-de-rosa, verde) e com motores "preparados" ou alterados para ganhar melhor desempenho. Esses jovens reclamam do tamanho reduzido da reta utilizada nos eventos do autódromo, que impossibilita suas motos de baixa cilindrada de alcançarem velocidade. Segundo eles, quando conseguem, já estão no final da reta, o que retira o gosto e a emoção dessa prática.

Horizontes Antropológicos, Porto Alegre, ano 16, n. 34, p. 159-187, jul./dez. 2010 
carros mais novos que podem ser "tunados", caso dos jovens de maior poder aquisitivo, a exemplo de alguns que participam do Londrina Tuning Clube. Quase todos participam, em maior ou menor grau, dos eventos do autódromo e de "rachas" de rua. Os encontros do autódromo servem como local de lazer, de encontro, de negócios de automóveis, de peças, de acessórios, uma vez que há vários estandes de lojas e de oficinas do ramo, além de se reforçarem laços de sociabilidade e de possibilitarem os desafios de competição entre os donos dos automóveis apresentados.

O quadro, portanto, é diferente do contexto das décadas de 1970 e 1980, quando os "rachas" eram praticados, no Brasil, por jovens das classes médias urbanas com maior poder aquisitivo (Carmo, 2001). Isso aponta para o fato de que, atualmente, mesmo os jovens com menor poder aquisitivo têm acesso a um dos bens preferenciais de consumo do século XX - o automóvel. ${ }^{12} \mathrm{E}$, além disso, eles transformam os seus carros e motos, personalizando-os à sua imagem, à medida de suas possibilidades e inseridos em uma ampla rede de trocas de serviços, peças e favores. ${ }^{13}$

A associação de velocidade e juventude é um fenômeno social que data dos anos 1950, e foi eternizada pelos modelos paradigmáticos de rebeldia e de inconformismo juvenil relacionados aos carros, às motocicletas, às jaquetas de couro e ao rock. O gosto por motores e automóveis (não só da parte dos jovens) se explica pela centralidade que eles ganharam no imaginário ocidental. O automóvel e a velocidade são considerados como os traços centrais da revolução urbana e da vida moderna e impactaram de maneira profunda as relações sociais, sendo analisados por diferentes autores (Cunha, 2007; Featherstone, 2004; Sávio, 2002; Sennett, 1997; Virilio, 1996). Dentre os mui-

${ }^{12} \mathrm{O}$ processo de mundialização do capital e globalização da cultura inclui a possibilidade de extensão do consumo às outras classes sociais, mesmo que de forma desigual. Os jovens "rachadores" das classes populares realizam, dessa maneira, os valores de consumo e de aceleração, inclusive na busca do êxtase das sensações. Mudanças econômicas e políticas nos anos 1960 permitiram a parcelas de jovens brasileiros o acesso ao consumo (Madeira, 1986) e, posteriormente, maior visibilidade (Abramo, 1994), como alvos da indústria cultural e produtores de novas demandas de consumo.

${ }^{13}$ O mundo dos "rachadores" apresenta estilos, gostos, linguagens e símbolos de identificação diversos, dependendo da marca do carro ou da moto, do pertencimento de classe, dos locais de encontro. São chamadosa, por exemplo, de "titanzeiros" quando tem motos de baixa cilindrada ou de "dodgeros", "opaleros", "chevetteros", conforme o carro que possuem. Tais processos de diferenciação e de criação de estilos e de culturas juvenis seguem a lógica dos processos de tensão entre globalização e respostas locais, intrinsecamente ligados ao mercado e à indústria cultural (Appadurai, 1999; Blass, 2004; Costa, 2006; Featherstone, 1995, 1999; Feixa, 1998; Morin, 1986).

Horizontes Antropológicos, Porto Alegre, ano 16, n. 34, p. 159-187, jul./dez. 2010 
tos impactos, os acidentes e as mortes no trânsito ${ }^{14}$ colocaram a temática do risco em evidência, juntamente com outros riscos de caráter global e coletivo, frutos do desenvolvimento acelerado da ciência e da tecnologia, ou melhor, como efeitos secundários e contínuos do próprio processo de modernização (Beck, 2008; Giddens; Beck; Lash, 1997; Kanashiro, 2008; Rodrigo, 2008).

Mas a pesquisa com jovens "rachadores" se insere na tradição dos estudos sobre risco que abordam o plano da percepção e de suas implicações culturais (Douglas, 1994, 1996), com ênfase nos riscos vivenciados por parte daqueles que não o evitam, mas que buscam e valorizam sua experiência, como os empreendedores e os desportistas (Le Breton, 1991; Ribeiro, 2003).

É o caso dos jovens "rachadores" que buscam a adrenalina ${ }^{15}$ da velocidade como atores ativos, e o fato de ser uma prática ilegal, que causa acidentes e mortes, faz deles alvo de concepções e imagens estereotipadas. Com o objetivo de aprofundar o conhecimento sobre eles, mas sem pretender dar conta da diversidade desse universo, apresentaremos o percurso de três jovens, escolhidos em função de seus diferentes perfis, e analisaremos as três oscilações de sentidos, já citadas, que aparecem recorrentemente nas entrevistas e nas observações de campo: o risco entre rituais de passagem e passagens indeterminadas; o risco entre vertigem e controle; e o risco entre vida e morte e entre rito e jogo.

Esse recorte do material de pesquisa pretende aprofundar o tema central do artigo, a relação entre as condutas de risco e os percursos incertos e as passagens arriscadas e indeterminadas desses jovens, dando vida e voz a alguns deles, tentando não descontextualizar suas falas.

São três jovens, três percursos diferentes a serem apresentados: BrincaTitan, Rock-Dodge e Piloto V8. ${ }^{16} \mathrm{O}$ primeiro, Brinca-Titan, nos acolheu para

${ }^{14}$ Após a Segunda Guerra Mundial, o automóvel se tornou um fenômeno de massa e, com isso, o aumento de acidentes de trânsito e de mortes tornou-se um fenômeno social a ser analisado (Tapia-Granados, 1998 apud Marin; Queiroz, 2000).

${ }^{15} \mathrm{O}$ termo adrenalina refere-se, no sentido literal, à substância (hormônio) presente nas respostas do organismo aos estímulos externos e, no sentido figurado, à energia, à força, ao vigor (Houaiss, 2001). Os pesquisados utilizam o termo com recorrência para expressar as sensações produzidas na experiência com a velocidade, segundo eles, de prazer intenso e de muita excitação. É nesse sentido que os pesquisadores utilizam o termo.

${ }^{16}$ Esses nomes que atribuímos a eles têm o objetivo de garantir-lhes o anonimato e foram inspirados em suas narrativas e nos sentidos que eles atribuem às suas práticas. Esperamos ter tido sensibilidade para que eles possam se reconhecer na nossa tentativa de nomeá-los.

Horizontes Antropológicos, Porto Alegre, ano 16, n. 34, p. 159-187, jul./dez. 2010 
a entrevista em sua oficina mecânica especializada em motos e referência para "rachadores". A entrevista se transformou em uma conversa animada, com a participação de outros jovens que frequentam o local. Brinca-Titan tem perto de 30 anos, é casado e tem uma filha de seis anos. No seu primeiro trabalho em uma oficina mecânica, aos 11 anos de idade, ele começou a aprender sobre a mecânica das motos e com seu patrão conheceu o mundo dos "rachas". O gosto pelas motos e pelos "rachas" vem desde a infância, quando já "tirava racha" com sua bicicleta. Esse gosto ele expressa ao afirmar que pode "fazer isso 24 horas sobre 24 horas"; "tá no sangue isso aí, não tem como explicar".

O segundo, Rock-Dogde, ${ }^{17}$ tem 28 anos, é estudante universitário e sempre trabalhou como assistente administrativo. Realizamos a entrevista na universidade, mas foram muitas as conversas informais que tivemos ao longo da pesquisa, entremeadas com observações de campo, nas ruas, na praça, no autódromo, na sua casa, que também funciona como oficina de seu pai. Atualmente ele está sem emprego, sua mãe trabalha no serviço público e seu pai é mecânico e trabalha em casa na reparação de automóveis. Seu pai e seu tio sempre estiveram no ramo de compra, venda e reparação de carros. Seu pai fazia "rachas" quando jovem, inclusive com ele no banco de trás do carro, em uma época em que não havia obrigatoriedade do uso do cinto de segurança. Ele tem um irmão, sete anos mais novo, que também gosta e pratica "rachas" e manobras como burnout e "zerinho", mas que ele considera "muito louco" e irresponsável.

$\mathrm{O}$ terceiro, Piloto $\mathrm{V} 8,{ }^{18}$ nos convidou para fazer a entrevista na garagem da casa de um amigo, mecânico, no bairro onde mora, em um sábado, enquanto preparavam um churrasco. Vários garotos à sua volta participavam da conversa, na medida em que ele permitia, pois sua liderança no bairro fica evidente desde o começo da conversa. Ele tem aproximadamente 40 anos e o seu percurso é bastante singular em comparação aos jovens pesquisados. Ele participa de "rachas" ou "pegas" na cidade desde os anos 1980 e conhece muita gente dessa época e do automobilismo oficial que se iniciou então na cida-

\footnotetext{
${ }^{17}$ Agradecemos sua participação imprescindível em todo o processo de pesquisa, como assistente e "rachador", ele próprio, e conhecedor desse universo. Sem seu entusiasmo, sua sensibilidade e observações perspicazes, a pesquisa não teria sido possível.

${ }_{18}$ Motores V8 são fabricados com o bloco do motor em V, com quatro pistões para cada lado, daí o nome V8. Exemplos: Dodges Dart, Charger de 1969 até 1983, Ford Galaxie de 1967 até 1976. Eles fizeram história nos EUA em razão de sua potência.
}

Horizontes Antropológicos, Porto Alegre, ano 16, n. 34, p. 159-187, jul./dez. 2010 
de. Além disso, é conhecido hoje no meio dos "rachas" e vários jovens sabem o seu nome e o carro que possui, totalmente personalizado. ${ }^{19}$ Ele já foi casado duas vezes e atualmente mora sozinho na periferia da cidade, onde realiza um trabalho como educador social. Foi dependente de álcool e de drogas e há 14 anos não usa mais nenhuma substância, por essa razão acredita no trabalho de redução de danos para a dependência química. Ele se vê como referência para os jovens do bairro e considera os "rachas" um "exemplo produtivo de droga" em comparação às drogas ilegais e ao álcool. Desde a adolescência gosta de carros, sobretudo dos "V8": "nasci e cresci dentro de um V8".

\section{0 risco entre ritos de passagem e passagens indeterminadas}

Quando tem competição é o seguinte: se ele tá com pouca coisa na minha frente que dá pra eu relar na mão dele, então o que vou fazer, se dá pra eu relar nele, eu vou puxar ele pra trás pra eu avançar pra frente, é isso daí, o que manda mais no racha, a moto pode ser até um pouco mais fraca, se você conseguir segurar até o final no vácuo aí você apoda, ou cê pega no pé dele, puxa ele, ou dá um susto nele que ele vai perder, ele vai frear [...] cê anda com uma mão só, vai trocando as marchas, então cê segura ele com a outra mão e puxa ele pra trás... isso aí nós fazia direto, eu Juninho, um camarada meu, uma galera. (Brinca-Titan).

Com 14 pra 15 anos, meu pai resolveu me ensinar a dirigir, daí eu comecei ter a sensação do que é ter um volante nas mãos, aí eu comecei fazer minhas cagadas no trânsito, é a questão de você ter aquela sensação de superioridade masculina, você não admite que uma mulher fica parada na sua frente, não é só mulher, é mulher, japonês, idoso, nada que seja lerdo [...] na rua tem aquela de você fazer uma curva mais rápido que o oponente, de ter que arriscar mais pra ter maior êxito, se você tem que entrar naquela curva a 70, 60 por hora, o teu oponente tá com medo de entrar, mas você não pode ter o mesmo medo dele, depende da ocasião e da curva, cê fala eu vou dobrar o risco, risco é 60 , vou entrar a 120 na curva, eu vou deixar pra frear mais em cima da hora, porque eu sei que meu oponente vai frear antes. (Rock-Dodge).

19 São muitos e variados os grupos de "rachadores", conforme já assinalado. Esses grupos têm fronteiras fluidas e moventes e se constituem sempre em torno de um interesse comum, os motores e a velocidade. O que faz Piloto V8 ser muito conhecido, extrapolando os limites de seu grupo mais próximo, é que ele participa dos encontros do clube de carros dos "dodgeros", por exemplo, por que possui um carro V8, e dos eventos de "rachas" quinzenais do autódromo. Nessas ocasiões os vários grupos se encontram, se reafirmam, se enfrentam, redefinindo permanentemente as redes de trocas e de relações sociais.

Horizontes Antropológicos, Porto Alegre, ano 16, n. 34, p. 159-187, jul./dez. 2010 
"Pega" é o seguinte, tô vindo um ano pra cá e nós já temos treta eu e o camarada já tá meio enroscado um com outro na garganta, porque vai toda aquela coisa da rebeldia, aquele carro daquele cara lá, num sei o quê, "ego", "desafio" [...] ó, na rodovia eu tô acostumado a pegar Audi e BM e dar pau neles, não, dou pau bonito, de ir embora, largo pra trás e vou embora, sabe... mas é daquele jeito, tem que ter espaço, agora no autódromo por que que não tem V8? Como é que vou arrancar com um carro de três mil quilos com um carro de seiscentos? (Piloto V8).

A maioria dos jovens entrevistados começou a se interessar por motores e por "rachas" cedo, entre oito e dez anos, através de alguém da família - pai, tio, primo, irmão - de amigos, conhecidos ou patrões. É um universo fundamentalmente masculino, no qual são transmitidos conhecimentos sobre motores e, para alguns, a possibilidade de um ofício ou de uma profissão, como Brinca-Titan. Por outro lado, Rock-Dodge não adquiriu a profissão de mecânico do pai, apesar de conviver com ela desde pequeno: "Desde criança meu pai chegava em casa com dois, três carros, no outro dia voltava com mais cinco, daí tinha aquele ritual de ficar reformando o carro na garagem de casa ou me levava pra oficina pra mexer nos carros." Ele foi construindo seu percurso em outra direção, influenciado pela mãe que o incentivou a entrar na universidade. Já Piloto V8 aprendeu sobre motores e "rachas" com amigos e conhecidos: "Eu comecei a brincar com os Dodges mesmo eu era um moleque, com os Dodges moendo lá, nós chegava regaçando mesmo, tinha onde era a oficina, era point, tudo pequeninho." Mas Piloto V8 não fez desse conhecimento uma profissão, traçando um outro percurso, incerto e à maneira de um bricoleur ou de um prefigurador.

Referindo-nos aos conceitos de Mead (1971) e de Bourdieu (1982), podemos resumir os percursos de vida dos três "rachadores" no seu quadro intergeracional. Brinca-Titan segue a transmissão de seu primeiro patrão, mas transformou sua oficina em um local para "preparação" de motos, entrando, assim, em um novo nicho da economia "sobremoderna" e tornando-se referência para as novas redes de jovens. Piloto V8 talvez seja o que se mais se aproxima da figura de um precursor - prefigurador - de novos percursos. Ele se torna um dos "tios fundadores" do autódromo (assim apelidado pela geração seguinte), fruto de longas lutas com o serviço público e a economia privada, mas constata que essa institucionalização das corridas arriscadas não é suficiente. Como liderança e educador social, ele prefigura, então, a iniciativa 
de um trabalho informal de "redução de danos" 20 com jovens da periferia no sentido de colocar a "dependência" da velocidade no lugar da dependência do álcool e das drogas. Mas ele continua aventurando-se nos "pegas", mais radicais do que os "rachas", porque é "treta", é "rebeldia", é "pau bonito". Talvez, se as condições se apresentassem, ele se engajasse em novos dispositivos para garantir novos espaços para os jovens "rachadores" de motos com os quais convive. Rock-Dodge, de alguma forma, "rompe" o seu percurso de vida ficando entre, de um lado, a retomada do "racha" ao mesmo tempo transmitido e proibido por seu pai, antigo "rachador" e, por outro lado, a entrada em uma esfera mais informatizada de trabalho, estudo e planejamento de futuro.

Paralelamente à transmissão de conhecimentos, esses jovens adquirem e vão exercitando, ao longo de seus percursos, um conjunto de valores e de práticas próprios de uma masculinidade hegemônica tradicional (Almeida, 2000; Connell, 1997; Espada Calpe, [s.d.]; Kimmel, 1998). Os valores centrais dessa configuração, a competitividade, a agressividade e a coragem, se reatualizam na prática dos "rachas", na medida em que eles precisam ser permanentemente provados aos olhos de seus pares (mas também da polícia e das garotas). Com o risco de sermos parciais, enfatizamos como resultado principal da análise que o exercício dessa masculinidade hegemônica tradicional reforça o risco existente na prática dos "rachas". Os desafios lançados e respondidos publicamente são compreendidos como ritos permanentes de virilidade (Le Breton, 2009, p. 35), com características de "ritos de instituição" (Bourdieu, 1982), pois instituem e sancionam expectativas comuns na forma como esses jovens agem e constroem suas identidades pessoais e sociais.

O acompanhamento desses percursos nos leva a completar a compreensão desse estilo competitivo. Primeiro no sentido que Rock-Dodge expressa de não poder suportar que uma mulher conduza diante dele, e isso com um fundo de excitação que exerce o automóvel sobre a maioria dos condutores, mulheres inclusive. Mas os rachas se referem ainda a um reservatório de ideologias de virilidade que encontram seu ponto culminante no significado da própria palavra "racha", que quer dizer fenda causada por ruptura, mas que na linguagem popular se refere ao sexo feminino (vagina). Como verbo, dentre outros sentidos, "rachar" significa partir-se ou romper-se por excesso de

${ }^{20}$ Método utilizado para dependentes químicos de substituição do uso de drogas que causam mais danos por outras que causam menos danos. 
tensão, fazer em estilhas ou lascar, fender-se ou abrir fendas, ferir ou atingir com violência (Houaiss, 2001). Esse mesmo tipo de ação de se partir ou de se romper, em consequência de choques ou de derrapagens e descontroles, pode se estender, por analogia, à atitude viril diante do sexo feminino.

Entretanto, é certo que essas significações de virilização não são completamente ritualizadas, mas oscilam, elas próprias, entre um lado "duro" que se refere à coragem e à agressividade, e que mesmo os acidentes não podem desfazer, e um lado "mole" ou vulnerável. Piloto V8, por exemplo, deixa transparecer o que chamamos de "risco de virilização" quando fala das ligações sucessivas que teve com várias mulheres, com as quais ele brigava, incessantemente, até se sentir "chamado" pelo carro, que nunca está pronto, mas que "obedece", "funciona" mais lealmente às diretrizes do piloto e permite-lhe uma retomada do que ele pensa ser o seu "eu". Confrontados com as transformações das relações de gênero, parece que os "rachadores" fundamentalizam, de alguma maneira, as normas herdadas dos ritos de virilidade, se não conseguem moderá-las um pouco no quadro das estruturas familiares herdadas, a exemplo de Brinca-Titan, que afirma ter parado de "rachar" depois que sua filha nasceu. Ou como um "rachador" de origem japonesa demonstrou, ao relatar e aceitar a copilotagem, cada vez mais frequente, das mulheres nos circuitos e nas ruas de Tóquio. ${ }^{21}$. Podemos compreender esses riscos de virilização ainda mais se levarmos em conta que as mudanças "sobremodernas" modificam as transgressões "modernas", pois os "rachadores" não expressam seus atos de mobilização com objetivos coletivos de transgressão (referência às interdições sexuais), mas com fins mais ambíguos de individualização, ao mesmo tempo, “duros" e vulneráveis, privados e públicos (Beck-Gernsheim, 1980).

Outro elemento importante nesses percursos de passagens indeterminadas dos jovens "rachadores" é o papel da transgressão. Se, em suas narrativas, os desafios, as competições, as performances e os acidentes tornam-se história, memória coletiva, que cria lendas e feitos heroicos, ${ }^{22}$ a transgressão é

21 Ele trabalha há anos no Japão, onde realiza drifting, uma modalidade de corrida na qual se "desliza" nas curvas, acelerando e freando ao mesmo tempo.

22 A criação dessas legendas ou feitos heroicos respalda-se no fato de que todos conhecem os nomes e, mais importante, os carros, as motos e os detalhes dos desafios e das manobras, como expressa Piloto V8: "O Mima, aquele do Opalão, que tem uma Variant vermelha, que tinha uma Caravan amarela de arrancada, o cara negro." Esses processos dão aos jovens o sentido de pertencimento em face da tensão atual entre homogeneização e singularização.

Horizontes Antropológicos, Porto Alegre, ano 16, n. 34, p. 159-187, jul./dez. 2010 
um aspecto a ser problematizado, pois pode ser outro elemento que reforça a "entrada em cena" do risco, potencializado por conta da ilegalidade das práticas e da provável presença da polícia. Entretanto, a transgressão tem outro sentido que não o da confrontação aos pais, à polícia, ao instituído que se almeja transformar, como é o caso da transgressão juvenil dos anos 1950 na figura paradigmática de James Dean. Partimos da premissa que os "rachadores" transgridem muito mais no sentido de uma rebelião latente contra uma sociedade supervigiada e com a tendência a amortecer os corpos-máquinas e as consciências-técnica. Isso porque existe uma ambiguidade com respeito à velocidade no seio de suas relações com a autoridade dos pais e da polícia. ${ }^{23}$ É como se eles buscassem, através da velocidade, experiências de intensificação das sensações corporais, reagindo ao mundo massificado e às formas de controle social e de autocontrole. ${ }^{24} \mathrm{~A}$ ideia de "atrito" (do grego tribé), desenvolvida por Pais (2004, p. 12), pode ajudar a entender essa relação entre transgressão, risco e culturas juvenis. Segundo o autor, o sentido é de ocupação do espaço urbano, como um protesto latente para se fazer visível, através de corpos que se confrontam. ${ }^{25}$ No caso de práticas ilegais, como os "rachas", quando o arriscar-se se faz acompanhar de tensão e de medo, há também a sensação do "instinto do instante" e a do reconhecimento, tão valorizadas nas sociedades contemporâneas por permitirem a expressão da individualidade e a possibilidade de se ganhar um nome.

$\mathrm{Na}$ construção dessas lendas heroicas, por vezes a máquina toma o lugar do sujeito e da sua competência, ganhando vida própria com sua performance definida por sua potência. Como expressa Rock-Dodge, a propósito do carro

23 A exemplo da relação de Rock-Dodge com seu pai, também "rachador" na juventude, mas que não quer que o filho corra. Mesmo recebendo "broncas", o filho sabe que o pai não consegue impedir o sorriso de satisfação quando relata que o carro "preparado" pelo pai venceu um "racha". A exemplo também da relação arbitrária de alguns policiais com os "rachadores", por vezes multando e apreendendo o carro, outras aceitando propinas, outras, ainda, trocando informações técnicas sobre motores num campo comum de interesses.

${ }^{24}$ De acordo com Sennett (1997), a modernidade produziu uma intensificação dos sentidos, mas amortecendo-os, ao mesmo tempo, pois expôs os corpos à rapidez dos acontecimentos e das referências, obrigando-os à passividade.

25 A exemplo dos graffiters que trazem a periferia e a pobreza para os muros e edifícios do centro das cidades, com suas inscrições e desenhos (Pais, 2004); dos skatistas que conquistam o espaço urbano com movimentos de deslize e de rapidez (Pociello, 1995); dos surfistas de trem (Le Breton, 1991; Sévilla, 1997); e dos motoboys, para quem o risco e a velocidade não estão relacionados ao lazer, mas ao trabalho e, com códigos próprios, buscam um lugar nas vias de circulação dos centros urbanos (Scarpellini, 2004).

Horizontes Antropológicos, Porto Alegre, ano 16, n. 34, p. 159-187, jul./dez. 2010 
antigo que não podia "colocar pra correr" em função do alto custo financeiro com sua reparação: "Como os carros são carros antigos, e você não pode ficar judiando, correndo o risco de bater, quando alguém chama pro racha a gente fala assim, eu tenho um motor debaixo do capô e eu não preciso provar nada pra você porque você sabe o que meu caro corre." Ou então no sentido que deu um rapaz que faz "rachas" de moto, ao afirmar não haver competição nos "rachas" de motos, pois todos são conhecidos ou amigos, o que há é competição entre motores, é a moto melhor preparada que ganha. Essa relação dos jovens com suas máquinas nos remete à próxima oscilação de sentido.

\section{0 risco entre vertigem e controle}

Antes não tinha muitas opções, agora tem, muda pistão, virabrequinho, comando de superalta, média alta, é relações de moto, diminui tamanho de roda, carburação, é o principal da moto, carburador médio, grande, depende de qual lugar você vai andar, mas o que manda mais mesmo, que até todo mundo briga, é um comando de superalto, é supercaro, tem moto aí de 125 que dá pau em moto de 1000 cc, na carcaça é 125 , só que o que tem dentro ninguém sabe, né, então a gente faz uma supermoto, cada vez mais ela tá voltando a ser uma bicicleta, porque a gente vai tirando tudo, a gente coloca frente de bicicleta, roda de bicicleta, isso moto de arrancada, né, quanto menor, quanto menos peso, melhor. (Brinca-Titan).

Meu irmão é mais insano, esses dias de madrugada ele parou num cruzamento, tava chovendo e ele ficou fazendo zerinho no cruzamento, dando cavalo de pau e eu grudado no banco, morrendo de medo. E tô acostumado, quando vi tava morrendo de medo, porque você não sabe, né, pode quebrar alguma coisa, pode errar e acertar um poste, dei bronca nele: "Meu, cê tem que parar com essas loucuras, porque isso daí é muita insanidade cê fazer num dia de chuva, num lugar apertado", porque o carro dele é grande também. (Rock-Dodge).

Tem a ver com controle e não com descontrole, concentrado no último, sensibilidade no último, tanto que você vê, a molecada que vai andar no autódromo, os que tocam mesmo, cê não vê eles dando risada nunca. Adrenalina e o cara aqui ó, tal, atento a tudo porque cê não pode ficar atento só no carro, o teu desempenho, o cara do seu lado [...] a gente vinha vindo ó, pé crachado ${ }^{26} \mathrm{o}$ cara rodou

${ }^{26}$ No jargão dos “rachadores", com o pé fundo no acelerador.

Horizontes Antropológicos, Porto Alegre, ano 16, n. 34, p. 159-187, jul./dez. 2010 
no meio da expressa, a gente ia dar no meio, foi só redução baixando marcha, redução, tiramos pro lado e fomos embora, se é outro cara ia dar no meio, e ia morrer todo mundo. Tem que ter sangue frio. (Piloto V8).

A relação com o risco presente nos "rachas" ganha, nesse contexto descrito, novos significados nos quais, por exemplo, a busca de vertigem não é contraditória com o sentimento de controle ou domínio do automóvel, mas cujos significados se entrelaçam de maneira complexa. Isso porque esses jovens estabelecem uma estreita relação e grande familiaridade com a tecnologia dos motores, desde muito cedo, o que lhes dá um sentimento de autonomia e de individualidade, propiciado pelos automóveis, além do fascínio que a tecnologia e a velocidade exercem no imaginário ocidental contemporâneo. ${ }^{27}$

Todos os jovens nesse universo têm um conhecimento aprofundado sobre motores e do que é necessário fazer para prepará-los para correr, bem como conhecem pessoas que fazem comércio de carros, motos, peças e profissionais especializados. Eles conhecem os motores e os problemas que apresentam, inclusive de maneira sensorial: "conheço pelo som do motor"; "é o melhor cheiro do mundo", e os carros e as motos parecem se estender de seus corpos.

Se a oscilação discutida no item anterior aponta para uma "vertigem de virilidade", essa segunda, entre vertigem e controle, vai apontar, como veremos, no contexto das transformações "supermodernas", para uma "vertigem de controle" que se situa entre as mobilizações técnicas aceleradas e os mecanismos que aliam corpo e máquina. A ela conferimos um lugar central na análise, pois elas têm um papel primordial para os "rachadores".

De maneira geral, existe para todo automobilista atualmente um superrito de passagem que se tornou, aos olhos de muitos jovens, um "sacramento" das sociedades "sobremodernas": a formação e o exame para a carteira de motorista. O que esse exame verifica é a capacidade do futuro condutor de alargar a coordenação imediata das operações mentais (emoção-razão) e dos membros do seu corpo na direção de uma coordenação mais circunspecta de um grande número de saberes e gestos técnicos, bem como dos códigos de circulação. Entretanto, isso não é suficiente para os jovens "rachadores", que querem não

27 Não seria exagerado afirmar que esses jovens são criadores de suas máquinas e, nem tampouco, que elas ganham personalidade, num processo de "contaminação simbólica" em que as características pessoais dos jovens as "informam" e vice-versa, permitindo-lhes se apresentarem publicamente a partir delas.

Horizontes Antropológicos, Porto Alegre, ano 16, n. 34, p. 159-187, jul./dez. 2010 
somente provar as evoluções das tecnologias automobilísticas como também, e sobretudo, querem se "automobilizar" de uma maneira que solicita, ao mesmo tempo, mais risco e mais coordenação. Em seus percursos, eles apresentam movimentos entre razão-técnica, de um lado, e corpo-máquina, de outro, e para alcançar a vertigem e retomar o controle é preciso coordenar essa relação e isso se dá através da competência, de acordo com suas afirmações. Eles não se contentam com coordenar as operações necessárias para conduzir, mas ousam ir adiante com essas competências, se "autoacelerando", poderíamos dizer, com a ajuda de tecnologias cada vez mais sofisticadas - às vezes se voltando para modelos antigos e carros velhos, verdadeiras "carcaças", às vezes para bólidos ou carros novos "turbinados" - e a mobilização de seus corpos, através das máquinas.

Nessa oscilação vertigem-controle, a relação homem-máquina desempenha um papel importante, a ponto de alguns jovens expressarem uma vontade própria da máquina com a qual a vontade deles deve negociar. Rock-Dodge expressa muito bem isso quando afirma: "Tava voltando pra casa, em ponto morto, sossegado, ouvindo um sonzinho. Daí passou um carro por mim, um Gol, o carro, bem inferior em questões de motor e tal e me chamou, tem umas linguagens tal, dá umas aceleradas e vai, liga o alerta, e me chamou pro racha." Essa "vontade" dos carros que "chama" para o "racha" se complementa com a ideia de passividade do sujeito em relação ao automóvel e à velocidade, conotando forças contra as quais o sujeito pode pouco ou quase nada. Os jovens expressam isso através das ideias de "vício", "droga" ou "doença": "pra quem gosta disso, é uma doença"; "porque ó, eu saí dum casamento de cinco anos, graças a Deus, sabe? Casei de novo com meu carro e tô muito bem. É um vício, mesmo quando era casado era viciado nesse troço"; "é um vício, nunca tá pronto. Toda semana, ó hoje cê tá vendo ele assim, semana que vem cê vai olhar vai tá diferente, ou é motor, ou é alguma coisa, roda, pneu”; "aí pegou a doença da ferrugem"; "a droga é o nosso carro"; "tá no sangue isso aí".

\section{0 risco entre vida e morte e entre rito e jogo}

Aprendi com um ex-patrão meu, o primeiro patrão com quem trabalhei, ele tirava racha, bastante, eu tinha 11 anos, aí foi onde eu comecei a gostar, né, dessa brincadeira, que é uma brincadeira, né, entre amigos, então, hoje eu dei uma parada por causa da minha filha, mas mexo, trabalho com bastante rapazes aqui

Horizontes Antropológicos, Porto Alegre, ano 16, n. 34, p. 159-187, jul./dez. 2010 
que adoram tirar racha, tanto faz na rua como no autódromo, eu aconselho mais no autódromo, eu acho bem mais legal no autódromo, mas é, sei lá, uma adrenalina, né, uma adrenalina, cê tá no racha, você para, você não consegue parar de tremer, é aquela loucura. (Brinca-Titan).

A primeira sensação é de muita adrenalina no sangue [risos], só que eu acredito também, acredito não, eu tenho certeza que depois da adrenalina, muita endorfina vai ser jogada no sangue também, ou que, pelo menos pra mim, tem uma sensação de prazer muito grande ao praticar aquilo. E, até depois que a gente para, a gente racha ou corre com o carro, ou faz alguma manobra desse tipo, a gente para e fica com aquela adrenalina no sangue, a gente fica empolgado, a gente fica falando disso, daquilo, aquilo ali fica assim, cê fica sem ar, cê fica fascinado. $\mathrm{Eu}$, a primeira vez que eu fiz um borrachão, aquilo que eu falei procê de travar e derreter o pneu do carro até estourar, a primeira vez que eu fiz aquilo eu não dormi uma semana. A adrenalina parecia que ficava correndo, eu tenho um vídeo disso gravado até hoje [...] uma semana sem dormir, lembrando daquilo. É uma loucura gigante, a gente sai com aquela sensação de prazer, é muito associado à música. Eu acho que pra quem gosta de motores pesados um, um bom e velho rock'n'roll, aquele bem pesado, bem frenético assim, te deixa, te deixa muito excitado. (Dodge-Rock).

Os caras subia com Maverick, qual rua que subia a Piauí, pra relar e sair fogo e descendo pra fazer esfria-saco, a gente fala. Esfria-saco era você vinha com tudo e voava, naquela época era que nem Os Gatões. Acabava com o carro, mas era uma beleza $[\ldots]$ a molecada que vai andar no autódromo, os que tocam mesmo, cê não vê eles dando risada nunca. (Piloto V8).

Essa última oscilação abrange, de alguma maneira, as duas outras oscilações precedentes. Não podemos deixar de examinar as relações circunscritas entre vida e morte, entre rito e jogo, pois estudos atuais de referência para o assunto tratam as condutas de risco como modalidades de interpelação da morte a fim de buscar sentido e gosto de viver (Le Breton, 2007a, 2007b). Entretanto, a oscilação entre rito e jogo emergiu de maneira surpreendente do material e pesquisa.

Falar de passagem da vida à morte remete, inicialmente, a uma compreensão tradicional sempre associada a uma visão bioteológica de "ciclo de vida”. Falar, em seguida, de um percurso do rito ao jogo leva a uma definição simplificada de rito no seu sentido mais estrito de estado de ordem, celebrado 
à repetição, sacralizado ou evidenciado, rompendo com a ordem cotidiana e reduzindo a incerteza (se não a ritualiza novamente). $O$ rito passa ao jogo quando a ordem se transforma em um estado de desordem criador, de movimentos inovadores, de festas e de flows que tendem, entre outras coisas, a reduzir o tédio rotineiro. Fundamentalmente, os seres humanos, não estando conectados imediatamente com seus instintos, são levados a oscilar entre rito e jogo, lembrando, de maneira geral, o entreato que se abre às oscilações entre os dois: o risco.

As sensações corporais, mentais e grupais (“adrenalina”, "prazer”, "excitação", "loucura", "zoar", "brincar", "tirar onda", "fazer bobeiras") se expressam de maneira geral e ficam evidentes na citação de Dodge-Rock: "sensação de prazer", de "empolgação" e de "fascínio". Ele se refere a um ambiente coletivo de jogo, de fruição e de festa, por vezes sustentado pelo álcool e por drogas. É como se os "rachadores" tivessem trazido o gosto pelos jogos da infância.

O sentido de "brincadeira" faz parte dos percursos desses jovens. No percurso particular de Dodge-Rock está inserido em uma estrutura de socialização familiar paradoxal, pois seu pai transmitiu ao filho o gosto pelos motores e pelos "rachas", mas, ao mesmo tempo, não quer que seu filho o faça. É como se o deixasse participar dos jogos, das "brincadeiras" e "besteiras" que ele mesmo fazia, mas o advertindo para não fazer o mesmo. Sua atitude ambivalente se expressa quando ele pergunta ao filho uma noite, ao ouvi-lo chegar, adivinhando que ele tinha "rachado": "Andou na frente?" Ao ouvir a resposta afirmativa, sorriu, mas veio a "bronca": "Você é louco, ficar correndo na via pública, seu carro é antigo, vai que quebra, vai que cruza alguém na frente."

Como dito anteriormente, a análise dos trabalhos de Le Breton (2007a, 2007b) mostram que uma parcela de jovens, em sofrimento, corre riscos como forma de responder a esse sofrimento e como tentativa de encontrar sentido à sua existência, escapando da falta de sentido, da indiferença e do isolamento. Eles correm riscos, então, não porque buscam morrer, mas para poder viver. As narrativas dos "rachadores" nos levam a enfatizar outro aspecto da questão, porque nem todos têm seus percursos marcados, de maneira acentuada ou particular, pelo sofrimento, tampouco se referem a ele em seus depoimentos. Eles também não falam de risco, mas sim, e sobretudo, de "brincadeira", di- 
versão, prazer (comparando ao sexual), ${ }^{28}$ relaxamento e, mais raramente, de fuga. Então, para assumir as aporias de per-correr constantemente o risco entre vida e morte, prolongamos a análise para a outra relação oscilante entre jogo e rito. Os "rachadores" arriscam para escapar da indiferença e do tédio cotidiano e para desfrutar, pelo menos momentaneamente, dos jogos que dão "sal" à vida. A maioria, como Brinca-Titan e Dogde Rock, acentua o caráter de "brincadeira", mesmo que outros levem a atividade mais a sério, como Piloto V8, que faz uma distinção entre piloto e condutor, ou outros que falam de treino, de talento e de domínio de técnica com estatuto de esporte. Interessante notar que Piloto V8, dentre todos os outros, foi o que mais vivenciou experiências de risco em seu percurso, como o uso e a dependência de drogas, passagem pela criminalidade e, agora, chega a submeter as questões de vida e de morte a um espírito de disciplina e de precaução, inclusive financeira.

À primeira vista a passagem da vida à morte, sempre possível nos percursos dos "rachadores", encontra-se negada em proveito do vivenciado mais imediato, o incidente/acidente, seguido de um gesto heroico e viril: nem mesmo pernas e mãos amputadas ${ }^{29}$ os fazem parar, como demonstram os inúmeros relatos, como o de Dodge-Rock sobre seus tios: "Um perdeu um dedo num acidente de moto também, o outro que corria de moto tem platina, parafuso na perna por causa de acidente de moto, então os irmãos dele tão tudo estropiado por causa de racha de moto." 30

Mas as reações aos acidentes demonstram também que a morte aparece no horizonte desses jovens, mesmo que de forma subliminar, subentendida nos

${ }^{28}$ Eles fazem constantemente referência ao prazer sexual para comparar ao prazer que sentem no "racha": "é tão bom como o sexo"; "é como trepar, é melhor que trepar".

${ }^{29} \mathrm{O}$ caso mais exemplar é o do acidente de um rapaz conhecido que tem uma loja de pneus e está sempre presente nos eventos de "rachas" do autódromo. O acidente de moto que sofreu, por ocasião de um desafio em uma estrada periférica, tem sido descrito de forma exaustiva pelos jovens, principalmente os detalhes de ter perdido uma perna e de ter tido sua mão encontrada próximo ao local do acidente e recolhida para enxerto. Há fotos do que restou da moto na internet e um vídeo contendo seu depoimento em um culto evangélico. Alguns jovens afirmaram que ele voltará a andar de moto, assim que conseguir uma perna e um braço mecânicos.

${ }^{30}$ Os garotos que participaram da entrevista de Brinca-Titan parecem dizer que, mesmo que se machuquem, o fato de estarem vivos e de não terem nenhuma sequela grave pode relativizar a percepção de risco: "Eu bati a 140 com a minha moto e no outro dia já tava andando de novo"; "eu já caí umas quatro vezes de moto, nunca aconteceu nada, nem um arranhão, nada". Brinca-Titan reafirma: "Tem vários amigos nossos aí que estão com sequela, mancando, bateu tirando racha, e não para, não para, o cara tá até hoje tirando racha."

Horizontes Antropológicos, Porto Alegre, ano 16, n. 34, p. 159-187, jul./dez. 2010 
relatos sobre mudança de comportamento ou sobre estratégias desenvolvidas depois de terem vivenciado ou presenciado um acidente. Brinca-Titan afirma que "o melhor é no autódromo" e Rock-Dodge que: "A partir do acidente eu passei a ter mais responsabilidade e mais cuidado no trânsito, se quero rachar numa via pública, procuro uma de madrugada que não tenha movimento." ${ }^{31}$

O medo poderia ser um indicador de que da morte não está totalmente ausente de seus horizontes, mas são poucos os que afirmam ter medo. Um rapaz que participou da entrevista de Piloto V8 diz que "na moto dá medo, a gente morre" e Rock-Dodge admite que é "medroso com relação a me exibir de moto, eu ficava tentando aprender a empinar e já abaixava a moto, ficava com medo de cair". A maioria, como Brinca-Titan, diz não ter medo: “Ó, medo, medo não tem, o único medo nosso é a polícia [...] medo não tem não", ou Rock-Dodge que afirma: "Eu tinha menos medo naquela época. Medo, medo eu tenho mais agora, até porque você passa a ser maior de idade, a ter meu carro, vai doer mais no meu bolso, e que vou ter que responder criminalmente por isso se alguma coisa der errado"; ou ainda Piloto V8, que acaba revelando: "Vamos falar a verdade, rola de ter que pagar o carro dos outros. É mais financeiro, a realidade é o seguinte, não tem medo, é precaução financeira, só precaução financeira."

\section{De volta cos três percursos}

Nossas interpretações procedem de maneira tateante, sempre sujeitas a novas verificações, não podendo ter a pretensão de conclusão. Mas, para sintetizar as reflexões apresentadas, reforçamos nossa hipótese principal que emergiu no curso da pesquisa, segundo a qual a reatualização dos valores e práticas próprias de uma masculinidade hegemônica tradicional (o que chamamos de risco de revirilização) figura como horizonte organizador dos percursos dos "rachadores". Ela se alimenta dos esforços de competição, de controle e de

\footnotetext{
31 Um outro rapaz, que também participou da pesquisa, nos explicou que o seu grupo de motoqueiros passou a fazer "rachas" em uma estrada vicinal alternativa porque ela é menos perigosa do que a outra, que é referência para "rachas", além do objetivo também de despistar a polícia. Esse mesmo rapaz também se referiu a um "pressentimento" para não ir "rachar": "De vez em quando dou um tempo, quando bate um pensamento de não, hoje eu não vou, porque não tô sentindo bem, pode ser que vai acontecer alguma coisa."
}

Horizontes Antropológicos, Porto Alegre, ano 16, n. 34, p. 159-187, jul./dez. 2010 
jogo, mas continua sendo o fator que pré-estrutura estes últimos. A vertigem de reafirmação de um estilo de masculinidade influencia a retomada de controle e as vertigens de reencontro do jogo. "Fender-se" e "competir" ressoam, de alguma forma, no "derrapar" e no "controlar", bem como sobre o "brincar" e o "fazer bobagem".

Se confrontamos os percursos dos "rachadores" às figuras que Le Breton (1991; 2007b) desenvolveu para circunscrever as condutas de risco, podemos observar que esses jovens atravessam todas elas. Encontramos entre eles características de "apagamento", ${ }^{32}$ que se pode expressar na adaptação dos corpos à máquina, como os garotos que não comem para emagrecer e ficar mais leves para os "rachas" de moto, ou os que se deixam ir pela vertigem, mesmo que por alguns segundos; características de "sacrifício", ${ }^{33}$ exemplificado na dependência emocional com relação aos motores e à tecnologia - o carro ou moto como "droga"; características de "afrontamento", ${ }^{34}$ a exemplo dos élans violentos de "arrebentar"; "pé crachado", "dar no meio"; "dar um pau", como expressa Piloto V8: "Se pego ele na rodovia, eu passo em cima"; e, finalmente, as características de "ordália", ${ }^{35}$ a exemplo do risco de relar no outro a $140 \mathrm{~km} / \mathrm{h}$ de moto, como conta Brinca-Titan: "Cê anda com uma mão só, vai trocando as marchas, então cê segura ele com a outra mão e puxa ele pra trás." Nas suas significações, os "rachadores" deixam entender que eles se veem menos confrontados com morte, e mais arriscando a vida, precisamente, a supervida acelerada, controlada, desfrutada para retornar à vida cotidiana, à sobrevida rotineira.

Todas essas interpretações nos levam a corrigir nossa compreensão inicial a respeito da "sobremodernidade" e da estrutura desses ritos de passagem transformados. Sugerimos que estamos diante de uma hipermodernidade ou de uma intermodernidade (Bauman, 1992; Kordes, 2007; Robertson, 1992),

32 Essa figura é definida por Le Breton (2007b, p. 21) como uma atitude de "effacement de soi dans la disparition des contraintes d'identité" encontrada, por exemplo, no uso de drogas, na errância ou na participação de seitas.

33 Figura na qual se "joue la partie pour le tout", ou seja, o jovem sacrifica uma parte de si para salvar o essencial, a exemplo da anorexia, das escarficações corporais ou o uso abusivo de drogas (Le Breton, 2007b, p. 21).

${ }^{34}$ Figura que representa as confrontações com relação aos outros, através da violência e de incivilidades.

35 Arriscar ou jogar "le tout pour le tout". Todas as condutas de risco dos jovens teriam uma tonalidade ordálica, mas, segundo o autor, "la démarche n'est nullement suicidaire, elle vise à relancer le sens, à mettre l'individu au monde" (Le Breton, 2007b, p. 21). 
na qual os ritos de passagem podem sobreviver, mas estando impregnados de estruturas processuais de percursos indeterminados ou arriscados, nos quais os motivos de individuação interferem nos motivos de reagrupamento (redes), as estruturas privatizantes são interdependentes das estruturas públicas, as tendências de mundialização se interpenetram com aquelas de localização. E, finalmente, as evoluções de abertura das relações entre gênero se tensionam com forças de fechamento, próprias da masculinidade hegemônica tradicional.

\section{Referências}

ABRAMO, W. H. Cenas juvenis: punks e darks no espetáculo urbano. São Paulo: Anpocs, 1994.

ALMEIDA, M. V. de. Senhores de si: uma interpretação antropológica da masculinidade. Lisboa: Fim de Século, 2000.

APPADURAI, A. Disjunção e diferença na economia global. In: FEATHERSTONE, M. (Org.). Cultura global: nacionalismo, globalização e modernidade. Petrópolis: Vozes, 1999.

AUGÉ, M. Não-lugares: introdução a uma antropologia da supermodernidade. Campinas: Papirus, 1994.

BALANDIER, G. Le Dédale: pour en finir avec le XXe siècle. Paris: Fayard, 1994.

BAUMAN, Z. Moderne und Ambivalenz: das Ende der Endgültigkeit. Hamburg: Argument, 1992.

BECK, U. Risikogesellschaft: auf dem Weg in eine andere Moderne. Frankfurt/ Main: Suhrkamp, 1986.

BECK, U. "Momento cosmopolita" da sociedade de risco. Com Ciência, n. 104, 10 dez. 2008. Disponível em: <http://www.comciencia.br/comciencia/?s ection $=8 \&$ edicao $=41 \& \mathrm{id}=501>$. Acesso em: $12 \mathrm{dez} .2008$.

BECK, U.; BECK-GERNSHEIM, E. Riskante Freiheiten. Frankfurt/Main: Suhrkamp, 2000. 
BECK-GERNSHEIM, E. Das halbierte Leben: Männerwelt Beruf, Frauenwelt Familie. Frankfurt/Main: Suhrkamp, 1980.

BOURDIEU, P. Les rites comme actes d'instituition. Actes de la Recherche en Sciences Sociales, n. 43, p. 58-63, juin 1982.

BLASS, L. M. da S. Desfiles de carnaval e tribos urbanas: a diversidade no efêmero. In: PAIS, J. M.; BLASS, L. M. da S. (Org.). Tribos urbanas: produção artística e identidades. São Paulo: Annablume, 2004. p. 211-234.

CAILlOIS, R. Los juegos y los hombres: la máscara y el vértigo. México: Fondo de Cultura Económica, 1986.

CARMO, P. S. Culturas da rebeldia: a juventude em questão. São Paulo: Senac, 2001.

CONNELL, R.W. La organización social de la masculinidad. In: VALDÉS, T.; OLAVARRÍA, J. (Ed.). Masculinidad/es: poder y crisis. Santiago de Chile: Isis Internacional; Facultad Latinoamericana de Ciencias Sociales, 1997. p. 31-48. (Ediciones de las Mujeres n. 24).

COSTA, M. R. da. Culturas juvenis, globalização e localidades. In: COSTA, M. R. da; SILVA, E. M. (Org.). Sociabilidade juvenil e cultura urbana. São Paulo: Educ, 2006. p. 11-27.

CUNHA, R. A pressa de chegar. Com Ciência, n. 93, 10 nov. 2007 Disponível em: $<$ http:/www.comciencia.br/comciencia/handler.php?section=8\&edicao= 30\&id=350>. Acesso em: 3 mar 2009.

DOUGLAS, M. Risk and blame: essays in cultural theory. London: Routledge, 1994.

DOUGLAS, M. La aceptabilidad del riesgo según las ciencias sociales. Barcelona: Paidós, 1996.

ESPADA CALPE, J. M. Hombres, motos y riesgo: androcentrismo y sexismo en el mundo de las motos. [s.d.]. Disponível em: $<$ http://www.telefonica.net/ web2/sword/default.htm>. Acesso em: 28 fev. 2010. 
FEATHERSTONE, M. Cultura de consumo e pós-modernismo. São Paulo: Studio Nobel, 1995.

FEATHERSTONE, M. Cultura global: nacionalismo, globalização e modernidade. 3. ed. Petrópolis: Vozes, 1999.

FEATHERSTONE, M. (Ed.). Automobilities: an introduction. Theory, Culture \& Society, v. 21, n. 4/5, p. 1-24, Oct. 2004.

FEIXA, C. El reloj de arena: culturas juveniles en México. México: Centro de Investigación y Estudios sobre Juventud, 1998.

GIDDENS, A.; BECK, U.; LASH, S. Modernização reflexiva: política, tradição e estética na ordem social moderna. São Paulo: Ed. Unesp, 1997.

HOUAISS, A. Dicionário eletrônico da língua portuguesa. ver. 1.0. Rio de Janeiro: Instituto Antônio Houaiss de Lexicografia, 2001. 1 CD-ROM.

HUIZINGA, J. Homo ludens: vom Ursprung der Kultur im Spiel. Reinbek: Rowohlt, 1963.

JEOLÁS, L. S. Les courses ilégales de voitures: le cyberespace comme terrain ethnographique. Altérités, Montréal, v. 5, n. 1, p. 54-64, 2008. Disponível em: $<$ http://www.alterites.ca/vol5no1/pdf/jeolas2008.pdf $>$. Acesso em: 21 out. 2009.

KANASHIRO, M. Controle do risco: uma tarefa infindável. Com Ciência, n. 104, 10 dez. 2008. Disponível em: <http://www.comciencia.br/comciencia/ handler.php?section=8\&edicao=41\&id=497>. Acesso em: 12 dez. 2008.

KIMMEL, M. S. A produção simultânea de masculinidades hegemônicas e subalternas. Horizontes Antropológicos, ano 4, n. 9, p. 103-117, out. 1998.

KORDES, H. Interkultureller Wandel-Interkulturealitaet-Interitaet. In: NICKLAS, H.; MÜLLER, B.; KORDES, H. (Hg.). Interkulturell denken und handeln: theoretische Grundlagen und gesellschaftliche Praxis. Frankfurt/ Main: Campus, 2007. p. 15-26.

LE BRETON, D. Passions du risque. Paris: Métailié, 1991. 
LE BRETON, D. La vie en jeu, pour exister. In: LE BRETON, D. (Dir.). L'adolescence à risque. Paris: Hachette Littératures, 2003. p. 22-53.

LE BRETON, D. Conduites à risque: des jeux de mort au jeu de vivre. Paris: PUF, 2007a.

LE BRETON, D. En souffrance: adolescence et entrée dans la vie. Paris: Métailié, $2007 b$.

LE BRETON, D. Des rites juvéniles de contrebande. In: YANNIC, A. (Cood.). Le rituel. Paris: CNRS Editions, 2009. p. 25-44. (Collection Les Essentiels d'Hermès).

MADEIRA, F. R. Os jovens e as mudanças estruturais na década de 70: questionando pressupostos e sugerindo pistas. Cadernos de Pesquisa, São Paulo, n. 58, p. 15-48, ago. 1986.

MARIN, L.; QUEIROZ, M. S. A atualidade dos acidentes de trânsito na era da velocidade: uma visão geral. Cadernos de Saúde Pública, Rio de Janeiro, v. 16, n. 1, p. 7-21, jan./mar. 2000.

MARQUES, A. P. “Outras transições?” Configurações e problemáticas de socialização juvenil. Cadernos do Noroeste: Série Sociologia, Braga, v. 21, n. 1-2, p. 141-161, 2003. (Sociedade e Cultura 5).

MAUSS, M. Sociologia e antropologia: v. 2. São Paulo: EPU, 1974.

MEAD, M. Culture and commitment: a study of the generation gap. New York: The Bodley Head, 1971.

MORIN, E. Cultura de massas no século XX: o espírito do tempo: necrose. 2. ed. Rio de Janeiro: Forense Universitária, 1986. v. 2.

PEIRANO, M. Rituais ontem e hoje. Rio de Janeiro: Jorge Zahar, 2003.

ORTNER, S. B. Uma atualização da teoria da prática. In: GROSSI, M.; ECKERT, C.; FRY, P. H. (Org.). Conferências e diálogos: saberes e práticas antropológicas. Blumenau: Nova Letra, 2007. p. 19-43. (25a Reunião Brasileira de Antropologia - Goiânia 2006). 
PAIS, J. M. Introdução. In: PAIS, J. M.; BLASS, L. M. da S. (Org.). Tribos urbanas: produção artística e identidades. São Paulo: Annablume, 2004. p. 9-22.

PAIS, J. M. Prefácio: buscas de si: expressividades e identidades juvenis. In: ALMEIDA, M. I. M.; EUGENIO, F. (Org.). Culturas jovens: novos mapas do afeto. Rio de Janeiro: Jorge Zahar, 2006. p. 7-22.

POCIELLO, C. Os desafios da leveza: as práticas corporais em mutação. In: SANT'ANNA, D. B. de (Org.). Políticas do corpo: elementos para uma história das práticas corporais. São Paulo: Estação Liberdade, 1995. p. 115120.

RIBEIRO, F. B. Os modernos cavaleiros do asfalto: risco e transgressão nas estradas portuguesas. Cadernos do Noroeste: Série Sociologia, Braga, v. 21, n. 4-5, p. 53-68, 2003. (Sociedade e Cultura 5).

ROBERTSON, R. Globalisation: social theoriy and global culture. London: Sage, 1992.

RODRIGO, E. O ambiente das inovações tecnológicas e o risco. Com Ciência, n. 104, 10 dez. 2008. Disponível em: <http:/www.comciencia.br/comciencia/ handler.php?section=8\&edicao $=41 \& \mathrm{id}=503>$ Acesso em: 12 dez. 2008 .

SAPIN, M.; SPINI, D.; WIDMER, E. Les parcours de vie: de l'adolescence au grand âge. Lausanne: Presses Polytechniques et Universitaires Romandes, 2007.

ST-GERMAIN, P.; MÉNARD, G. Des jeux et des rites. Montréal: Liber, 2008.

SÁVIO, M. A. C. A modernidade sobre rodas: tecnologia automotiva, cultura e sociedade. São Paulo: Educ, 2002.

SCARPELLINI, V. Usucapião. Folha de S. Paulo, São Paulo, 16 jun. 2004. Caderno Cotidiano, p. C2.

SEGALEN, M. Rites et rituels contemporains. Paris: Colin, 2009.

SENNETT, R. Carne e pedra: o corpo e a cidade na civilização ocidental. Rio de Janeiro: Record, 1997. 
SENNETT, R. Der flexible Mensch: die neue Kultur des Kapitalismus. Berlin: Goldmann, 2001.

SÉVILLAJ.-J. Surfistas de trem brincam com a morte. Le Monde Diplomatique, 1 abr. 1997. Disponível em: <http://www.diplo.com.br>. Acesso em: 1 abr. 1997.

VIRILIO, P. Velocidade e política. São Paulo: Estação Liberdade, 1996.

Recebido em: 28/02/2010

Aprovado em: 06/07/2010 